\title{
Study of Combination of Polymers with Bitumen
}

\author{
${ }^{1}$ Yuliya V. Sayfullina, ${ }^{2}$ Elena V. Muruzina \\ 1,2 Kazan Federal University \\ Email:sds-m7lab@mail.ru
}

Received: 20 ${ }^{\text {th }}$ August 2019, Accepted: 30 $^{\text {th }}$ September 2019, Published: $31^{\text {st }}$ October 2019

\begin{abstract}
We have considered a possibility of modifying the roofing bitumen by the developed mixed thermoplastic elastomer (TPE) in view of its increased resistance to atmospheric aging. We evaluated the preliminary selection of TPE composition with accordance to the time of dissolution in the bitumen melt and main physical and mechanical properties. In order to determine the best polymer and bitumen compatibility, we calculated the solubility parameter of polymer in hydrocarbon solvents in terms of the shortest dissolution time as well as determined the TPE solubility parameter. The proximity of these indicators demonstrates the successful compatibility of TPE in saturated bitumen maltenes. The assessment of physicotechnical properties of TPE and its components in bitumen showed that highdensity polyethylene (HDPE) and synthetic triple ethylene-propylene rubber (EPR) have a major influence. HDPE increases the heat resistance of polymer modified bitumen composition (PMB) and accelerates the dissolution of TPE in bitumen at processing temperatures. EPR is responsible for the low-temperature properties of PMB composition and increases resistance to atmospheric aging, however, it takes a long time to dissolve in bitumen. We as well used the widely used styrene-butadiene-styrene thermoplastic elastomer (SBS) to compare the modifying effect. Modification of bitumen by TPE is more visible than by SBS or individual components, especially at high concentrations ( $\geq 10 \%$ ), and allows to obtain high durability of PMB.
\end{abstract}

Keywords

Polymer Modified Bitumen Composition, Solubility Parameter, Modification, Properties, Thermoplastic Elastomer.

\section{Introduction}

Petroleum bitumen in Russia is widely used in construction as the chief component in waterproofing production, roofing materials, and road asphalt concrete. However, its removal from tars at Russian oil refineries does not meet modern requirements for the properties of bitumen (although in some cases attempts for improvement are made) as well as the durability standards [1]. One of the ways to improve the properties of bitumen is carried out by modifying one with polymers $[2,3]$. Polymer additives (up to $15 \%$ ) give bitumen significantly improved properties. The quality is improved due to the creation of an asphalt-polymer structure with simultaneous plasticization of the interframe medium. The main focus during operation is preserving a stable (not stratifiable) elastically deformable structure in such a binder [4].

So far, the modification of bitumen with polymers has followed a long evolutionary path.

A number of researchers seek to improve the rheological parameters of PMB composition, characterizing it as a disperse system by its viscoelastic properties and capacity to dissolute in the maltene fraction of bitumen [5,6]. The available data suggests that some authors [7] obtained a chemical interaction of the carboxyl group of bitumen asphaltenes and polymer. In [8] we discovered a cross-link of the metaoxysilane group of bitumen and the acetyl fragments of ethylene copolymer with vinyl acetate; the investigation of nanomodification of bitumen is presented[9]. The use of significant industrial waste concentrations as bitumen modifiers have proved to be cost-effective[10, 11]. The most common and effective bitumen is SBS (styrene-butadiene-styrene rubber) or DST (divinyl-styrene thermoplastic elastomer). This thermoplastic elastomer has its polyvinyl aromatic blocks congregated in the domains that are dispersed in a continuous elastic matrix. When being in a solid glassy state, these domains act as a filler which is chemically bonded to the elastic phase. As a modifier, such fillers increase heat and frost resistance as well as improve the elasticity of the bitumen composition. However, SBS (DST) has insufficient weather resistance and, therefore, durability. It is not resistant to ultraviolet and ozone, which is due to the presence of double bonds in the main chain [12], and gets preliminary dissolved in a solvent (fuel oil, flux oil) to increase its compatibility with bitumen. It was therefore intended to create a mixed thermoplastic elastomer with good modifying effect (polymer mixture obtained by mechanical means [13]) (TPE) which had the advantages of DST while being devoid of its shortcomings. The TPE components were as follows: ethylene-propylene rubber (EPR/EPDM) - has good elasticity, resistance to atmospheric aging, frost resistance; polyethylene (HDPE) - has heat resistance, reasonable strength, but insufficient frost resistance; isoprene rubber (SIR) - improves the adhesion of modified bitumen to the reinforcing base and mineral fillers, increases the interval plasticity of the composition. 
The TPE composition as a bitumen modifier was selected on the basis of the effect of each component on the dissolution time and basic physical and mechanical properties. Successful structure formation of PMB composition is primarily influenced by the thermodynamic affinity of bitumen and polymer [14]. Potential compatibility is determined by solubility parameters: the mutual compatibility of components depends on their numerical closeness. The aim of the study is to find the optimal TPE composition for roofing bitumen BND 40/180, determine their compatibility parameters and evaluate the role of each component in comparison with mixed TPE and traditional divinyl-styrene DST (SBS).

\section{Methods}

In our study, we used the roofing bitumen BNK-40/180 with a high concentration of the oil component (>25\%). The DST-30 R-01 divinyl-styrene thermoplastic elastomer and the TPE mixed thermoplastic elastomer (consisting of EPDM-40, SIR-3 and HDPE in a ratio of 1: 1:2) were used as a modifier. The block copolymer thermoplastic elastomer (DST) was used to compare the results during bitumen modification.

In order to facilitate the introduction of DST into bitumen, it had been previously dissolved in a plasticizer for 3-4 hours, stirring at a temperature of $120-140^{\circ} \mathrm{C}$. Then this mixture was added to bitumen heated to $160-180^{\circ} \mathrm{C}$ and stirred until a homogeneous mixture was formed.

In order to find the solubility parameter of the mixed TPE, we dissolved it in various organic solvents and determined its dissolution time rate. The organic solvent solubility parameter adequate for the shortest TPE dissolution time was taken as the solubility parameter of the latter.

Penetration of P25 and P0 of polymer modified bitumen compositions was tested in compliance with GOST 1150578; the softening point (SP) was measured with a Ring and Ball apparatus (RBA) in compliance with GOST 1150673; the brittle point was measured with a Fraas apparatus in compliance with GOST 11507-78.

\section{Result and Discussion}

To obtain polymer modified bitumen compositions for roofing, low-viscosity bitumens are used, in which paraffinnaphthene oils predominate. The bitumen modifier must be capable of dissolving in these bitumen fractions, i.e. must to be non-polar.

In order to preliminarily select the optimal ratio of the components in the TPE, we created a series of samples with the following EPDM:HDPE ratio $=80: 20,70: 30.60: 40,50: 50$. We used bitumen BNK 40/180 as an object of our research.

As can be seen in table 1 below, the reduction of elastomeric phase from 80 to $50 \mathrm{pts}$ wt in the TPE reduces the time of elastomer dissolution in bitumen by $1.5 \ldots 2$ times. It is likely that EDPM swells and dissolves in bitumen at a temperature of its processing $\left(150-180^{\circ} \mathrm{C}\right)$ more slowly than polyethylene. In this case, the softening point (SP) rises from 41 to $86^{\circ} \mathrm{C}$. A slight decrease in penetration together with a temperature drop from 25 to $0^{\circ} \mathrm{C}$ are worth noting. This, perhaps, indicates an improvement in the low-temperature properties of TPE modified bitumen.

\begin{tabular}{|c|c|c|c|c|c|c|c|}
\hline \multirow{2}{*}{ No. } & \multirow{2}{*}{$\begin{array}{c}\text { TPE composition } \\
\text { (EPDM:HDPE) }\end{array}$} & \multirow{2}{*}{ Composition } & \multicolumn{2}{|c|}{ Preparation } & \multirow{2}{*}{$\begin{array}{c}\text { Softing } \\
\text { point, }{ }^{\circ} \mathrm{C}\end{array}$} & \multicolumn{2}{|c|}{$\begin{array}{c}\text { Penetration } \mathrm{x} \\
0,1 \mathrm{Mm}\end{array}$} \\
\cline { 4 - 7 } & & \multirow{2}{*}{$\mathrm{Time}, \mathrm{h}$} & $\mathrm{t},{ }^{\circ} \mathrm{C}$ & & $25^{\circ} \mathrm{C}$ & $0{ }^{\circ} \mathrm{C}$ \\
\hline 1. & - & BND-40/180 & - & - & 41 & 138 & 64 \\
\hline 2. & $80: 20$ & & 4,0 & $160-180$ & 79 & 122 & 115 \\
3. & $70: 30$ & BND-40/180+ & 3,6 & $160-180$ & 80 & 83 & 72 \\
4. & $60: 40$ & $10 \%$ TPE & 3,0 & $160-180$ & 82 & 66 & 57 \\
5. & $50: 50$ & & 2,5 & $160-180$ & 86 & 59 & 52 \\
\hline 6. & $50: 50$ & BND-40/180+ & 1,5 & $160-180$ & 45 & 89 & 38 \\
\hline
\end{tabular}

Table 1: PMB Composition Modified by TPE and its Properties

For further studies of the bitumen modification by TPE, the following ratio of components was devised: EPDM- $25 \%$, SIR- $25 \%$, HDPE- $50 \%$. The introduction of isoprene rubber into the TPE composition improves the adhesion of modified bitumen to the reinforcing base and mineral fillers as well increases the ductility interval.

To assess the compatibility of bitumen with mixed thermoplastic elastomer, the solubility parameter of the latter was determined. We prepared $10 \%$ solutions of thermoplastic elastomers in hydrocarbon solvents for this operation. 
Likewise, we determined the time of formation of a homogeneous solution at a temperature of $25^{\circ} \mathrm{C}$. The TPE dissolution time in the corresponding solvent was chosen as an indicator. The data obtained are shown in fig. 1.

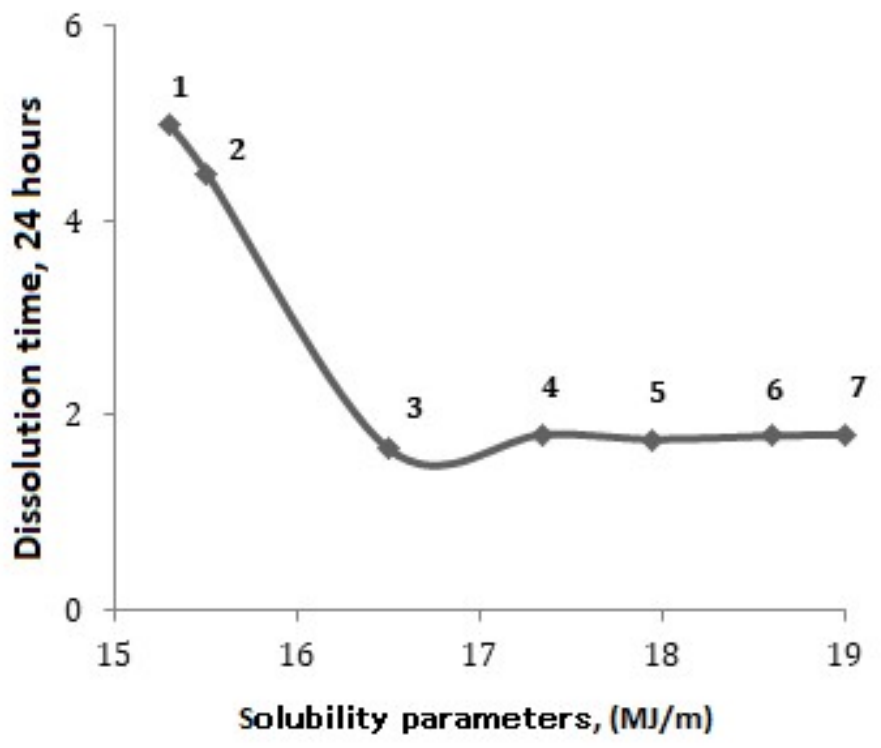

Fig. 1: Dependence of the TPE Dissolution Time of on the Type of Solvent

[1 - Heptane (Gasoline); 2- Ethanol; 3 - Turpentine; 4 - Carbon Tetrachloride; 5 - Methaxylol; 6 - Benzene; 7 - Chloroform.]

It can be seen from the figure that a pronounced minimum is observed near $\delta=16.5(\mathrm{MJ} / \mathrm{m} 3) 0.5$. Based on the known solubility parameters, the value of $\delta$ TEC was calculated taking into account each of its components: $\delta \mathrm{p}=16.66$ (MJ / m3)0.5. Analysis of the bitumen composition by its fractions solubility parameters (saturated maltenes 14.3 (MJ / $\mathrm{m} 3)$ 0.5, aromatic maltenes - $18.0(\mathrm{MJ} / \mathrm{m} 3)$ 0.5, resins - $18.6(\mathrm{MJ} / \mathrm{m} 3) 0.5$ ) allows to predict an adequate TPE solubility in the saturated and aromatic components of bitumen. However, a number of other factors also affect the solubility of polymers in bitumen: molecular weight, crystallinity, etc. These ought to be taken into account when assessing the compatibility of polymers with bitumen and their effect on the properties of modified bitumen.

We investigated the effect of individual TPE components on the properties of bitumen. Fig.2 shows the effect of individual TPE components: EPDM, SIR and HDPE, as well as DST and TPE at concentrations of 5.10 and $15 \%$ on the properties of BNK-40/180 bitumen.

As can be seen (Fig. 2 and Table 2), the major influence on the expansion of the PMB composition temperature interval is exerted by EPDM and HDPE. With an increase of EPDM concentration in bitumen from 5 to $15 \%$, the interval of BOD deformability increases from 75 to $120^{\circ} \mathrm{C}$. The introduction of $\mathrm{PMB}$ composition in bitumen to a greater extent than SIR and HDPE lowers the brittle point to $-46^{\circ} \mathrm{C}$.

In addition, EPDM gives the polymer modified bitumen compositions resistance to climatic influences. However, EPDM modified bitumen compositions modified are inferior to compositions modified by thermoplastic elastomers in terms of dissolution rate in bitumen at the processing temperature. 


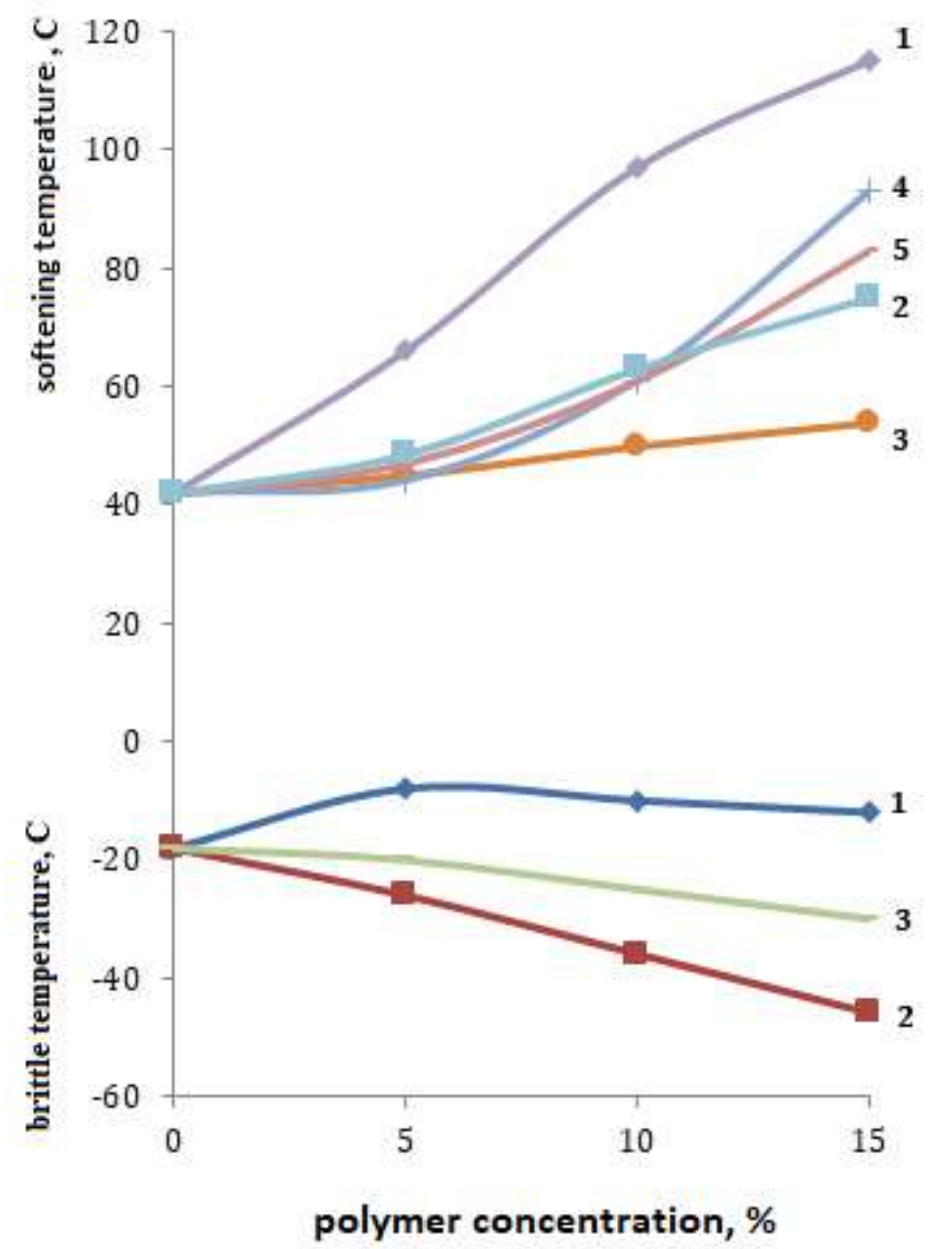

Fig. 2: Dependencies of Softening and Brittle Temperatures on Polymer Concentration in Bitumen [1 - BND-40/180 + HDPE; 2 - BND-40/180 + EPDM; 3 - BND-40/180 + SIR; 4 - BND-40/180 + TPE; 5 - BND + DST]

When PMB compositions have their thermoplastic content increased up to $15 \%$, a significant increase in heat resistance of up to $115^{\circ} \mathrm{C}$ can be seen, which significantly exceeds this indicator of bituminous compositions with EPDM and SIR with the same content in bitumen.

Polyethylene has a significant effect on the properties of TPE and PMB compositions. This is due to the similar solubility parameters of HDPE and saturated bitumen maltenes. Therefore, a significant proportion of the thermoplast dissolves in the oil fraction, thereby modifying bitumen as a whole. It accelerates the TPE dissolution in bitumen at processing temperatures $\left(150-180^{\circ} \mathrm{C}\right)$. Its application makes it possible to obtain TPE in the form of granules or highly dispersed powder.

The addition of SRS to bitumen, similarly to SKEPT, extends the PMB ductility interval, but to a lesser extent (Table 2 and Fig. 2.). The advantage of SIR is its adhesive ability, which allows to increase the PMB cohesive strength, as well as adhesion to various substrates. 


\begin{tabular}{|c|c|c|c|}
\hline \multirow{2}{*}{ Composition } & \multirow{2}{*}{$\begin{array}{l}\text { Plasticity } \\
\text { interval, }{ }^{\circ} \mathrm{C}\end{array}$} & \multicolumn{2}{|c|}{ Penetration $\mathrm{x} 0,1 \mathrm{~mm}$} \\
\hline & & $25^{\circ} \mathrm{C}$ & $0{ }^{\circ} \mathrm{C}$ \\
\hline BND-40/180 & 59 & 138 & 64 \\
\hline BND-40/180+5\%EPDM & 75 & 102 & 58 \\
\hline BND-40/180+10\%EPDM & 99 & 72 & 54 \\
\hline BND-40/180+15\%EPDM & 120 & 67 & 49 \\
\hline BND-40/180+5\%SIR & 66 & 128 & 71 \\
\hline BND-40/180+10\%SIR & 76 & 112 & 80 \\
\hline BND-40/180+15\%SIR & 86 & 94 & 91 \\
\hline BND-40/180+5\%HDPE & 74 & 106 & 34 \\
\hline BND-40/180+10\%HDPE & 107 & 66 & 23 \\
\hline BND-40/180+15\%HDPE & 127 & 43 & 16 \\
\hline BND-40/180+5\%ind.comp.TPE & 84 & 83 & 31 \\
\hline BND-40/180+10\%ind.comp.TPE & 104 & 61 & 25 \\
\hline BND-40/180+15\%ind.comp.TPE & 118 & 57 & 25 \\
\hline BND-40/180+5\%TPE & 66 & 98 & 40 \\
\hline BND-40/180+10\%TPE & 89 & 53 & 30 \\
\hline BND-40/180+15\%TPE & 123 & 52 & 22 \\
\hline BND-40/180+5\%TPE & 73 & 67 & 27 \\
\hline BND-40/180+10\%TPE & 88 & 69 & 28 \\
\hline BND-40/180+15\%TPE & 115 & 73 & 32 \\
\hline
\end{tabular}

Table 2: PMB Composition with Individual TPE Components and its Properties

Thus, the evaluation of some PMB properties modified by individual TPE components allowed us to trace their influence on the bitumen properties. The heat resistance of modified systems is more affected by HDPE, and the lowtemperature bitumen properties, as expected, are improved to a greater extent by EPDM. Furthermore, this elastomer is resistant to ozone, radiation, and UV, which means better weather resistance of PMB composition using EPDM. We as well determined the effect of individual TPE components on the bitumen physicotechnical properties: SIR, EPDM and HDPE with different concentrations introduced into the bitumen melt together. The ratio of the components complied with their ratio in the TPE.

The introduction of this polymer mixture into bitumen leads to a slight increase in the softening temperature compared with the mixed TPE. Perhaps, HDPE has a greater effect on this indicator in an unbound state. In terms of ductility interval, the polymer mixture in the concentration range of $5-10 \%$ exceeds the values of BND-40/180 bitumen modified by TPE. Nevertheless, the mixed TPE exhibits better efficiency than a mixture of polymers at high concentrations $(\approx 15 \%)$. It is worth noting that the use of a mixture of elastomers and thermoplastics leads to a decrease in their dissolution rate in bitumen by 2.5 times compared to TPE. A similar situation can be seen when modifying DST bitumen: the best modifying effect is shown at polymer concentrations of $10-15 \%$. It is important to remember that, in order to obtain a homogeneous composition, DST is pre-dissolved by stirring in fuel oil, and then it is introduced into the bitumen melt. DST has higher physical and mechanical properties compared with TPE, but it is inferior in terms of water resistance. In addition, TPE is a low-saturated polymer; therefore, its greater weather resistance is expected than that of DST. The TPE dissolution rate in bitumen is higher than in DST.

Thus, the physicotechnical properties of BND-40/180 bitumen modified by a mixture of sequentially introduced components and DST are slightly higher compared to bitumen modified by TPE. Nevertheless, at polymer concentrations of more than $10 \%$ in bitumen, the superiority of mixed TPE can be seen.

It is worth mentioning that, in production, the dissolution time of the polymer modifier in bitumen should be minimal. Therefore, the use of mixed TPE in bitumen is most preferable in comparison with the use of individual polymers in bitumen.

Thus, TPE is well combined with BND-40/180 bitumen and it shows a better modification effect at higher concentrations than with DST, especially at low temperatures.

\section{Summary}

This paper studies the possibility of modifying roofing bitumen by mixed TPE containing HDPE + SIR + EPDM. We selected the combination of the components on the basis of the most adequate solubility conditions in bitumen. We have established a favourable TPE compatibility in low viscosity bitumen. We discovered the concentration 
dependencies of the effect of individual TPE components in bitumen on the plasticity interval of PMB composition. HDPE shows to have a major influence on TPE. HDPE increases the dissolution rate and increases the composition heat resistance. EPDM increases the TPE heat resistance and protects the compounds from the effects of ozone, radiation and UV.

It is established that TPE does not delaminate the system when it is dissolved in bitumen, which indicates a synergistic effect of the components in the finely divided composition. This leads us to a conclusion that a mixed TPE is not a purely physical mixture.

We have as well established that bitumen get a greater modifying effect with TPE rather than with traditional DST, especially at high concentrations.

The undoubted advantage of using mixed TPE in the production of modified bitumen is that it is supplied in the form of fine granules or highly dispersed powder.

\section{Conclusions}

The technology of dissolution and physical and technical properties play the significant role in selecting the TPE composition for the modification of bitumen.

Our study has established that, in order to obtain a better bitumen-polymer compatibility, it is preferable to calculate the solubility parameters of both.

The possibility of varying the composition and concentration of TPE components based on the purpose of bitumen provides a large scope of activity for research

\section{Acknowledgements}

The work is performed according to the Russian Government Program of Competitive Growth of Kazan Federal University.

\section{References}

[1] Dzhumaeva O., Solodova N.L., Emelyanicheva E.A. Compounding in bitumen production technologies // Vestnik of Technological University. 2016. Vol.19. No.5. Pp.43-48.

[2] Kemalov R.A., Kemalov A.P. The use of natural bitumen as a raw material in production of bituminous insulation materials // Oil economy [Oil]. 2014. No.11. Pp.140-143.

[3] Galdina V.D. Modified bitumens // Omsk, SybADI. 2019. 219 p.

[4] Ayupov D.A., Khamimullin Y.N., Makarov D.B., Kazakulov R.I. Theoritical aspects of lamination of polymerbitumen binders. Vestnik of Technological University, 2016, vol.19, no.23, pp.50-52.

[5] Wolphson S.I., Y.N. Khamikulin, Zakirova L.Y., etc. Modification of bitumens as a way to improve its operating properties // Vestnik of Technological University. 2016. Vol.19. No.17. Pp. 29-33.

[6] Múnera J.C., Alexander Ossa. Analysis of binary bitumen-polymer mixtures // RevistaFacultad de Ingenieria. 2014. (70). Pp.18-33.

[7] Ayupov D.A., Potapova L.I., Murafa A.V., Fakhrutdinova V.K., Khamikullin Y.N., Hozin V.G. A study of bitumen and polymer features // Izvestya KGASU. 2011. No.1(15). Pp.140-146.

[8] Khamilkullin Y.N., Ayupov D.A., Sundukov V.I., Kazakulov R.I., Gizatullin B.I. Non-laminant triple-component polymer-bitumen binders // Construction materials. 2017. No.10. Pp.51-55.

[9] Khozin V.G., Nizamov R.K., Starovoytova I.A, etc. Anomalous effects of changes in the viscosity of epoxy resins and the plasticity of bitumen with the introduction of carbon nanotubes // Construction materials. 2019. No. 1-2. Pp.1115.

[10] Kheemich T.S., Krivtsova T.V., Leinveber A.V. Technological schemes of bitumen modification by diluting additives of phenolic resin. Development of the road and transport complex based on the rational use of natural resources // Collection of scientific articles from VII All-Russian research and practice conference. 2012. Pp. 201204.

[11] Tonevitsky Y.V., Mognonov D.M., Ayurova O.D., Kuznetsov Y.N. Modification of road bitumen by production waste // Construction materials. 2016. No.11. Pp. 59-62.

[12] Krzysztof Zieliński, Michal Babiak, Maria Ratajczak, JacekKosno. Impact of Chemical and Physical Modification on Thermoplastic Chracteristics of Bitumen // ProcediaEngineering.2017. Vol. 172.P.1297-1304.

[13] Garmonov I.V. Synthetic rubber: monography // Garmonov I.V. Vol.2. L.: Chemistry. 1993. 560 P.

[14] Costantinides G., Schromek N., Battera M. Mescole bitumen-polimero: anomalienellerelazionitracostituzionedei componenti // Riv. combust. 1989. 43. No. 7-8. S. 239-245. 